\title{
Thermal and mechanical characterization of complex electrospun systems based on polycaprolactone and gelatin
}

\author{
Raffaele Longo $^{1}\left[\right.$ [ Michelina Catauro ${ }^{2} \cdot$ Andrea Sorrentino $^{3} \cdot$ Liberata Guadagno $^{1}$
}

Received: 11 June 2021 / Accepted: 14 January 2022 / Published online: 11 February 2022

(c) The Author(s) 2022

\begin{abstract}
Nowadays, continuous development of soft-electronics and wearable devices opens to the development needs of stretchable and flexible materials able to interface with the human body. In this scenario, biopolymers are particularly intriguing materials given their biocompatibility and biodegradability. For the application in this specific field the material requires several properties such as biological and mechanical performance and thermal stability. In this study, membranes able to fulfill some of these requirements are described. The electrospun membranes, composed of a blend of polycaprolactone (PCL) and gelatin (GN), have been produced in various configurations. The results show how blend or coaxial systems have different effects on both the interactions between the polymers and their thermal and mechanical properties. An important result of the chosen experimental conditions is the narrow dimensional distribution of the nanofiber diameters constituting the electrospun membranes. Thermal and mechanical tests evidenced that, by properly choosing the material composition and the method of the electrospinning process, membranes capable of withstanding high strain values before the failure can be obtained. In particular, optimizing the electrospinning process and using a blend PCL/GN with a mass ratio of 80/20, it is possible to increase the thermal stability up to $310{ }^{\circ} \mathrm{C}$ and confer to the sample the ability to reach a percentage of strain up to $350 \%$.
\end{abstract}

Keywords Electrospun membranes · Mechanical properties $\cdot$ Thermal properties $\cdot$ Coaxial electrospinning $\cdot$ Biopolymers

\section{Introduction}

In recent years, advances in flexible and stretchable electronics have enabled the development of soft wearable and implantable devices that can reliably and unimpeded interface with the surface of the human body [1]. These devices must be able to interface perfectly with the body, minimizing contact resistances and disturbances caused by mechanical sliding during movement [2].

From the recent literature, the development of functional green polymer emerges as a relevant field of innovation $[3,4]$. As regards the wearable devices, they are made of

Raffaele Longo

rlongo@unisa.it

1 Department of Industrial Engineering, University of Salerno, Via Giovanni Paolo II 132, 84084 Fisciano, Italy

2 Department of Engineering, University of Campania "Luigi Vanvitelli”, Via Roma 29, 813031 Aversa, Italy

3 Institute of Polymers, Composites and Biomaterials (IPCB), National Research Council of Italy (CNR), P.le E. Fermi, 1, 80055 Portici, NA, Italy materials that require to be strong and soft enough to wrap around the body, hence leading to a pleasant feeling of comfort [5]. This aspect requires the development of membranes with adequate dimensions and mechanical properties. Many techniques have been developed to manufacture these materials, such as sol-gel [6], chemical vapor deposition [7], and the layer-by-layer method [8]. However, the complex properties of these materials require the development of new manufacturing techniques. From this point, electrospinning has proven to be an effective approach to the preparation of functional materials [9]. Many new electrospinning techniques have been developed for the design of new materials $[10,11]$. Moreover, the electrospinning process allows obtaining nanofiber membranes suitable for being used as scaffolds [12], as drug delivery systems [13] and with the possibility to obtain nanocomposite nanofibers [14-16]. However, wearable and implantable devices often require good biocompatibility [17].

In particular, thermoplastic biopolymers used for these applications can be mainly of two types: natural (e.g., gelatin (GN), collagen, hyaluronic acid) characterized in general by biocompatibility and biodegradability, or synthetic 
(e.g., polycaprolactone (PCL), polylactic acid) characterized by better mechanical properties $[18,19]$. However, their combination can be particularly effective: on the one hand in fact natural polymers can guarantee relevant biocompatibility and, on the other hand, the synthetics can enhance the mechanical properties of the material [20]. Biopolymers are now greatly applied for several types of applications including the biomedical field [21].

In this study, the electrospinning process is used to produce GN and PCL membranes in blend and in coaxial systems, to understand how the configuration of the process acts on the thermal, mechanical properties and morphological features of the obtained membranes.

Even if several papers deal with the usability of electrospun membranes based on PCL and GN for biomedical applications (mainly as scaffold) [22-26], rarely thermal and mechanical characterization of these types of membranes have been simultaneously analyzed using different process configurations with the same chemical composition of the blend. Zhang et al. [26] already noticed that GN and PCL electrospun blend (50:50 mass/mass) can have a higher strain at break, up to $138 \%$. On the other hand, Yao et al. [25] proved that PCL/GN blend electrospun membranes in different mass ratio (1:4 to $4: 1)$ have strongly different mechanical properties, with the higher elongation at break reported at 4:1 mass ratio (PCL/GN), which is around $90 \%$, significantly lower than the results reported in our work (349\%). This result is most likely due to the fact that SEM images of membranes presented by Yao et al. show fibers with a very wide diameter distribution that could strongly affect the mechanical properties [27].

In particular, in the present paper PCL-GN-based electrospun membranes are produced in blend and in coaxial systems. Firstly, the morphology of the membranes is presented, then the mechanical properties are discussed in the light of the thermal investigation of the different membranes.

\section{Materials and methods}

\section{Materials}

Poly( $\varepsilon$-caprolactone) used for the membrane preparation was provided by Perstorp (Sweden), CAS N ${ }^{\circ} 24980-41-4$. It is a linear polyester characterized by a high molecular weight (about 80,000 Da) and was provided in the form of pellets (granules with an approximate diameter of $3 \mathrm{~mm}$ ). GN from Porcine skin type A used for the membrane preparation was provided by Sigma-Aldrich (CAS $\mathrm{N}^{\circ}$ 9000-708). Hexafluoro-isopropanol (HFIP) used for the polymeric solution has been purchased by Apollo Scientific Limited.

\section{Preparation of polymeric solutions for electrospinning}

The solutions were prepared by dissolving the polymers in HFIP. The mass percentage of $5 \%$ of the polymers in HFIP has been chosen for the formulations containing both components (PCL and GN). A percentage by mass of $6 \%$ of PCL has been chosen for the membranes composed of PCL alone. The percentage allows good spinnability and processability of the solutions that have been kept under stirring at $40{ }^{\circ} \mathrm{C}$ for $24 \mathrm{~h}$ just after the preparation to obtain complete dissolution of the components. In blend systems, PCL-GN (Blend 80:20), and PCL-GN (Blend 60:40) samples, the ratios $80 / 20$ and 60/40 refer to the mass ratio percentage of the two components.

The polymeric solutions have been fed at a flow rate of $1 \mathrm{~mL} \mathrm{~h}^{-1}$ to the injector of the electrospinning equipment (EC-CLI by IME Technologies, Spaarpot 147, $5667 \mathrm{kV}$, Geldrop, Netherlands, injector diameter of $0.8 \mathrm{~mm}$ ) and have been spun thanks to the electric field in a controlled climate room at $25{ }^{\circ} \mathrm{C}$ and $35 \%$ relative humidity.

In coaxial electrospinning, GN and PCL are spun in parallel using a coaxial injector that allows obtaining bilayer nanofibers. For the blend membrane, GN and PCL are solved in the same solution and spun using monoaxial electrospinning. The process parameters have been optimized for obtaining membranes with no evident defects. The optimized parameters are shown in Table 1 .

All the membranes have been kept in vacuum for $24 \mathrm{~h}$ after the production to remove any solvent residuals.

\section{Morphological analysis}

The morphological analysis has been performed using scanning electron microscopy (SEM) by which information about the size and the distribution of fibers has been obtained. The electrospun membranes have been metalized using an Agar Automatic Sputter Coater before SEM analysis. A thin layer of $\mathrm{Au}$ is deposed on the membrane surface to improve the quality of the morphological acquisitions. The analysis to obtain the fiber size distribution has been done using ImageJ software, whereas the data to obtain the pore diameter distribution using MATLAB software following the procedure is reported by Havlíček et al. [28] Distribution curves are normalized so that the area under the histograms is equal to 1 .

\section{Thermal analysis}

Thermogravimetric analysis (TGA) has been performed using Mettler Toledo TC-10 thermobalance in air 
Table 1 Electrospinning process parameters

\begin{tabular}{|c|c|c|c|c|}
\hline & Materials & $\begin{array}{l}\text { Concentration/g } \\
\mathrm{g}^{-1}\end{array}$ & $\begin{array}{l}\text { Injector-collec- } \\
\text { tor distance/cm }\end{array}$ & $\begin{array}{l}\text { Positive and negative } \\
\text { electrodes voltages/ } \\
\mathrm{kV}\end{array}$ \\
\hline \multicolumn{5}{|l|}{ \# } \\
\hline PCL & PCL & 6 & 25 & $17 /-2$ \\
\hline PCL-GN (blend 80:20) & $\begin{array}{l}\text { Blend } 80 \% \\
\text { PCL and } \\
20 \% \text { GN (in } \\
\text { mass) }\end{array}$ & 5 & 22.5 & $13 / 0$ \\
\hline PCL-GN (blend 60:40) & $\begin{array}{l}\text { Blend } 60 \% \\
\text { PCL and } \\
40 \% \text { GN (in } \\
\text { mass) }\end{array}$ & 5 & 22.5 & $18 / 0$ \\
\hline PCL-GN (coaxial core-shell) & $\begin{array}{l}\text { Core: PCL } \\
\text { Shell: GN }\end{array}$ & $\begin{array}{l}5 \\
5\end{array}$ & 24 & $22 / 0$ \\
\hline GN-PCL (coaxial core-shell) & $\begin{array}{l}\text { Core: GN } \\
\text { Shell: PCL }\end{array}$ & $\begin{array}{l}5 \\
5\end{array}$ & 24.5 & $20 / 0$ \\
\hline GN & GN & 5 & 24.5 & $14 / 0$ \\
\hline
\end{tabular}

atmosphere $\left(50 \mathrm{~mL} \mathrm{~min}{ }^{-1}\right)$ with $10{ }^{\circ} \mathrm{C} \min ^{-1}$ heating rate from 30 to $700{ }^{\circ} \mathrm{C}$.

Differential scanning calorimetry (DSC) has been performed using Mettler Toledo DSC 822e in $\mathrm{N}_{2}$ atmosphere $\left(50 \mathrm{~mL} \mathrm{~min}{ }^{-1}\right)$ from -50 to $250{ }^{\circ} \mathrm{C}$ with $10{ }^{\circ} \mathrm{C}$ heating rate.

\section{Structural analysis}

X-ray diffraction (XRD) measurements have been taken using a Bruker D8 Advance diffractometer at $35 \mathrm{kV}$ and $40 \mathrm{~mA}$.

\section{Mechanical characterization}

Mechanical characterization has been performed using Dual ColumnTabletop Testing Systems (INSTRON, series 5967-INSTRON, Norwood, MA, USA) in tensile tests. For each membrane, five samples have been prepared of $1 \mathrm{~cm}$ (width) per $5 \mathrm{~cm}$ (length) per $0.1 \mathrm{~mm}$ (thickness) in ambient conditions. The tensile tests have been performed lifting at $10 \mathrm{~mm} \mathrm{~min}^{-1}$ the beam and acquiring data about force and distance covered. Thus, the data are converted in stress-strain curves.

\section{Results and discussion}

\section{Morphological analysis}

SEM images have been acquired for all the membranes to obtain a wide range of information about the morphology. They are reported in Fig. 1.

The morphological parameters of the membranes are reported in Table 2 .
Figure 1 shows a monomodal narrow fiber distribution, as evidenced in Fig. 2, for all the membranes with no evident defects, with the formation of a non-oriented mat. The thinnest nanofibers are produced for the PCL $(\approx 490 \mathrm{~nm})$, but, however, nano-sizes are obtained also for the other systems (up to $890 \mathrm{~nm}$ ). Moreover, the fiber dimension also affects the pore size, as already reported in the literature. Generally, an increase in the fiber dimensions determines an increase of the pore dimensions [29].

\section{Thermogravimetric analysis}

TGA analysis is reported in Fig. 3.

The derivative TGA of electrospun GN and PCL are reported in Fig. 4.

PCL and GN are characterized by different thermal curves. On the one hand, PCL shows two steps of degradation. The first begins around $320^{\circ} \mathrm{C}$ and has its maximum rate of mass loss in DTG graph around $400{ }^{\circ} \mathrm{C}$, and is due to the rupture of the ester chains, leading to the formation of $\mathrm{H}_{2} \mathrm{O}, \mathrm{CO}_{2}$ and 5-hexenoic acid. Then, around $450{ }^{\circ} \mathrm{C}$, the second degradation peak leads to depolymerization, producing $\varepsilon$-caprolactone [30].

On the other hand, GN mass loss can be divided in three different steps: The first one (up to $100{ }^{\circ} \mathrm{C}$ ) corresponds to the loss of water, probably due to the water absorption because of the high hydrophilicity of GN. The second one (from 200 to $400{ }^{\circ} \mathrm{C}$ ) is caused by protein degradation, whereas the third one by the rupture and decomposition of the GN network [31].

As reported in Fig. 4, the steps of degradation of GN and PCL are still well visible also for the blend and the coaxial systems. In particular, for the coaxial systems, a visible acceleration especially in the first degradation step 

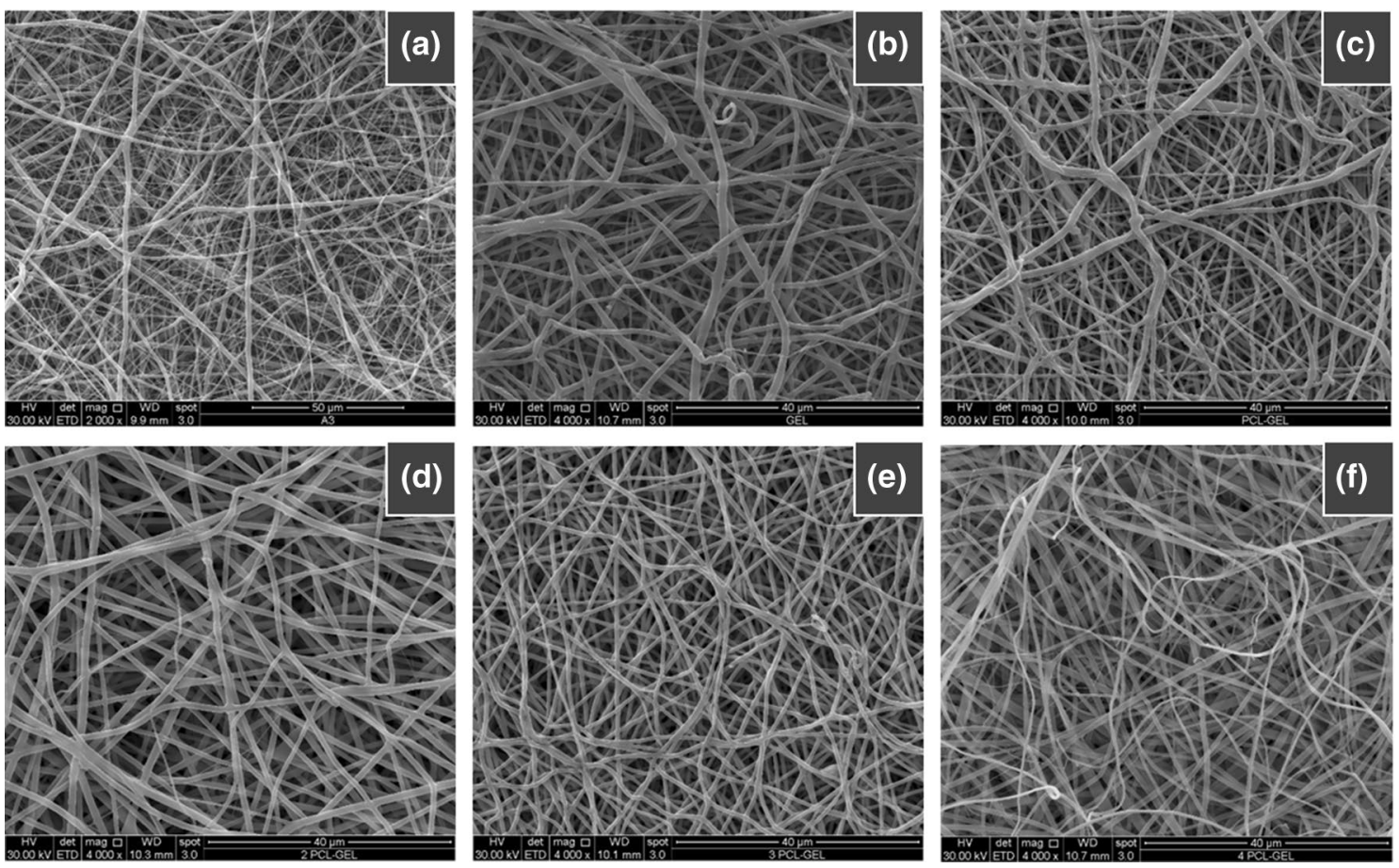

Fig. 1 SEM images of membranes: a PCL; b GN; c PCL-GN (blend 80:20); d PCL-GN (blend 60:40); e PCL-GN (coaxial core-shell); f GNPCL (coaxial core-shell)

Table 2 Fiber and pore diameter

\begin{tabular}{|c|c|c|c|c|c|c|c|}
\hline & & PCL & GN & $\begin{array}{l}\text { PCL-GN } \\
\text { blend } \\
\text { (80:20) }\end{array}$ & $\begin{array}{l}\text { PCL-GN } \\
\text { blend } \\
(60: 40)\end{array}$ & $\begin{array}{l}\text { PCL-GN (coax- } \\
\text { ial core-shell) }\end{array}$ & $\begin{array}{l}\text { GN-PCL } \\
\text { (coaxial core- } \\
\text { shell) }\end{array}$ \\
\hline Fiber diameter & Mean/ $\mu \mathrm{m}$ & 0.49 & 0.79 & 0.52 & 0.89 & 0.65 & 0.78 \\
\hline Pore diameter & Mean/ $\mu \mathrm{m}$ & 1.25 & 2.47 & 1.52 & 2.67 & 1.62 & 2.31 \\
\hline
\end{tabular}

is observed. This behavior is most likely due to the occurrence that in the coaxial configuration, the GN component is characterized by weaker interactions with PCL component; hence, its behavior tends to be more similar to GN alone.

\section{Differential scanning calorimetry}

DSC curves are reported in Fig. 5.

DSC graph of the PCL alone shows the melting point at $59.3{ }^{\circ} \mathrm{C}$, whereas the graph of GN manifests a very wide endothermic peak most likely due to water evaporation during the thermal scanning. This hypothesis is confirmed by the profile of the TGA and DTG curves shown in Figs. 3-4. The peak related to water evaporation is present also for the coaxial and blend systems, whereas it is absent for the PCL alone, confirming that water absorption is due to the high GN hydrophilicity, suggesting, as expected, that the more is the GN quantity, more wide and relevant is the peak (between 50 and $100{ }^{\circ} \mathrm{C}$ ) after the main melting point of PCL.

The melting peak of the PCL is affected by the presence of GN; its results strongly depend on the configuration process of electrospinning. In fact, the different results are observed for coaxial and blend systems. On the one hand, the PCL melting peak is slightly anticipated from $59.3{ }^{\circ} \mathrm{C}$ for the pure PCL to $58{ }^{\circ} \mathrm{C}$ for both the coaxial systems, whereas the blend systems show higher anticipation of the melting point according to the GN amount. For the system PCL-Blend (80:20), the melting point is detected at $57.0^{\circ} \mathrm{C}$, whereas for PCL-Blend $(60: 40)$ at $54.0^{\circ} \mathrm{C}$. The anticipation of the melting point suggests the formation of smaller crystallites that requires lower temperature energy to melt [32].

The DSC results are confirmed by XRD analysis, displayed in Fig. 6. PCL typical peaks at $21.5^{\circ}$ and $23.8^{\circ}$ (slightly shifted) are evident in the three diffractometric profiles. They are generated by the 110 and 200 reflections of the orthorhombic PCL crystalline structure [33]. 

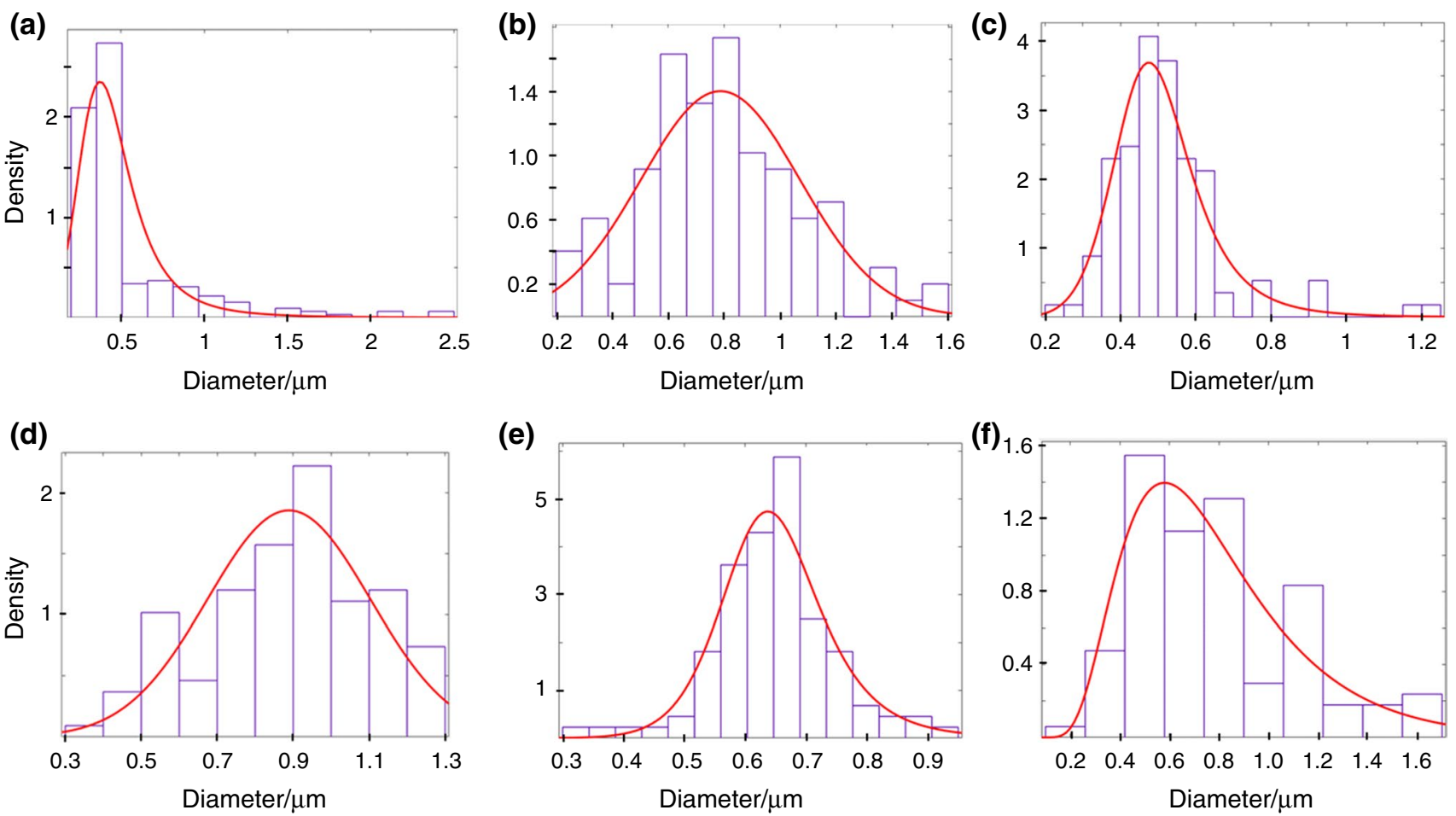

Fig. 2 Fiber diameter distribution of: a PCL; b GN; c PCL-GN (blend 80:20); d PCL-GN (blend 60:40); e PCL-GN (coaxial core-shell); f GNPCL (coaxial core-shell)

Fig. 3 Thermogravimetric analysis

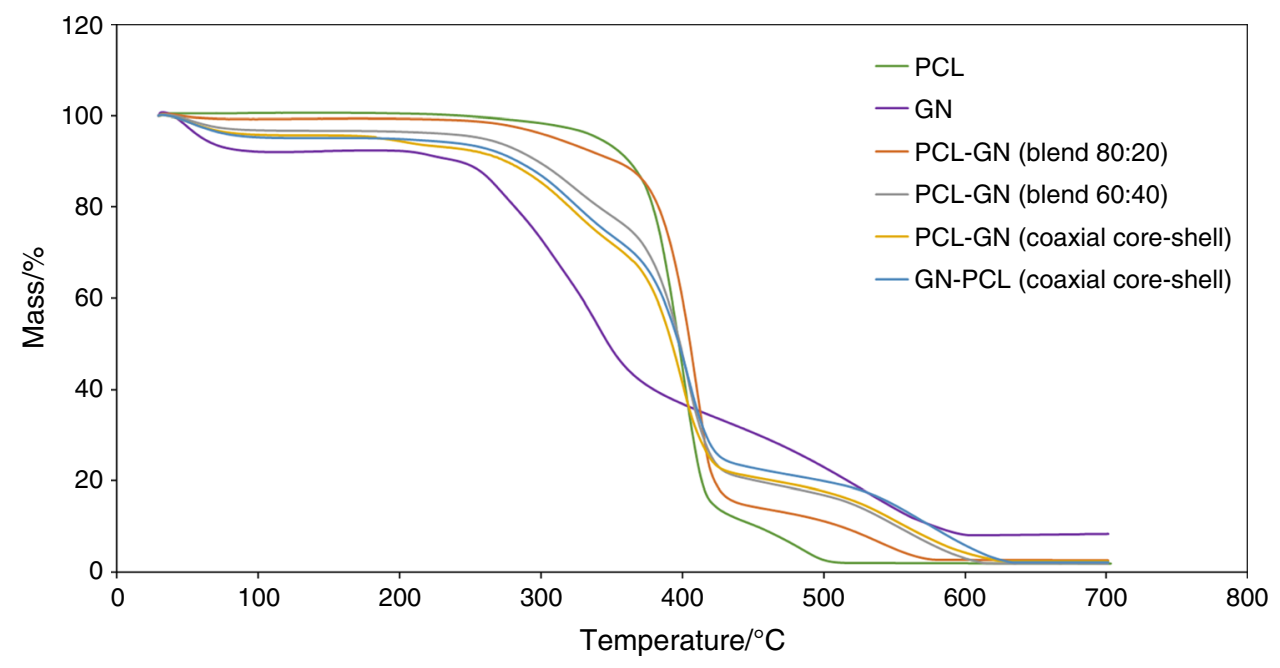

As expected, by increasing GN percentage an increase of the amorphous phase is observed. Furthermore, smaller crystallites size is well-evident by the profile of the diffractometric peaks corresponding to the samples obtained by the blends.

The half-height widening of the 110 and 200 reflections, which is diagnostic of smaller and defective crystals in the membranes from the blends with respect to that from pure PCL, is perfectly in line with the calorimetric results which highlight a decrease in the melting temperature of the membranes from blends compared to that obtained from the pure polycaprolactone.

\section{Mechanical characterization}

The mechanical properties of the membranes have been studied in tensile mode to understand how the composition of the polymeric system and the process configuration affects the 
Fig. 4 Derivative TGA of PCL and GN

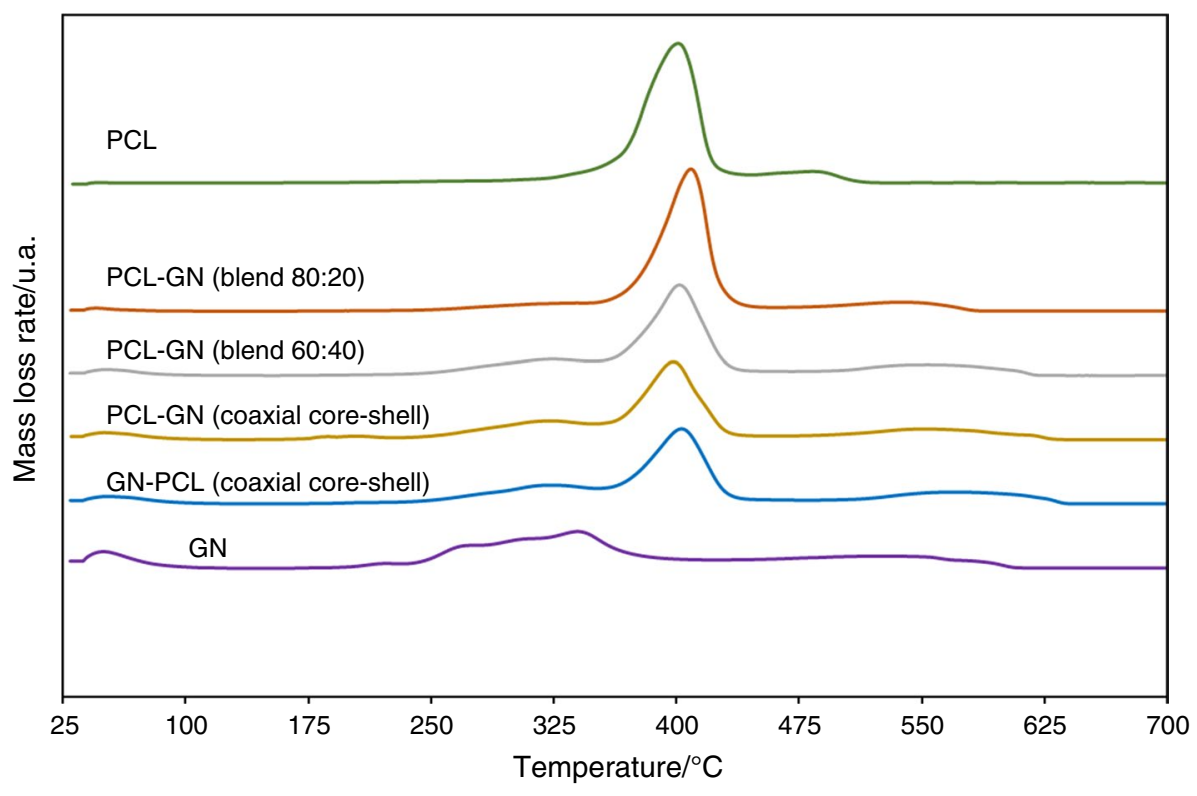

Fig. 5 DSC of the membranes

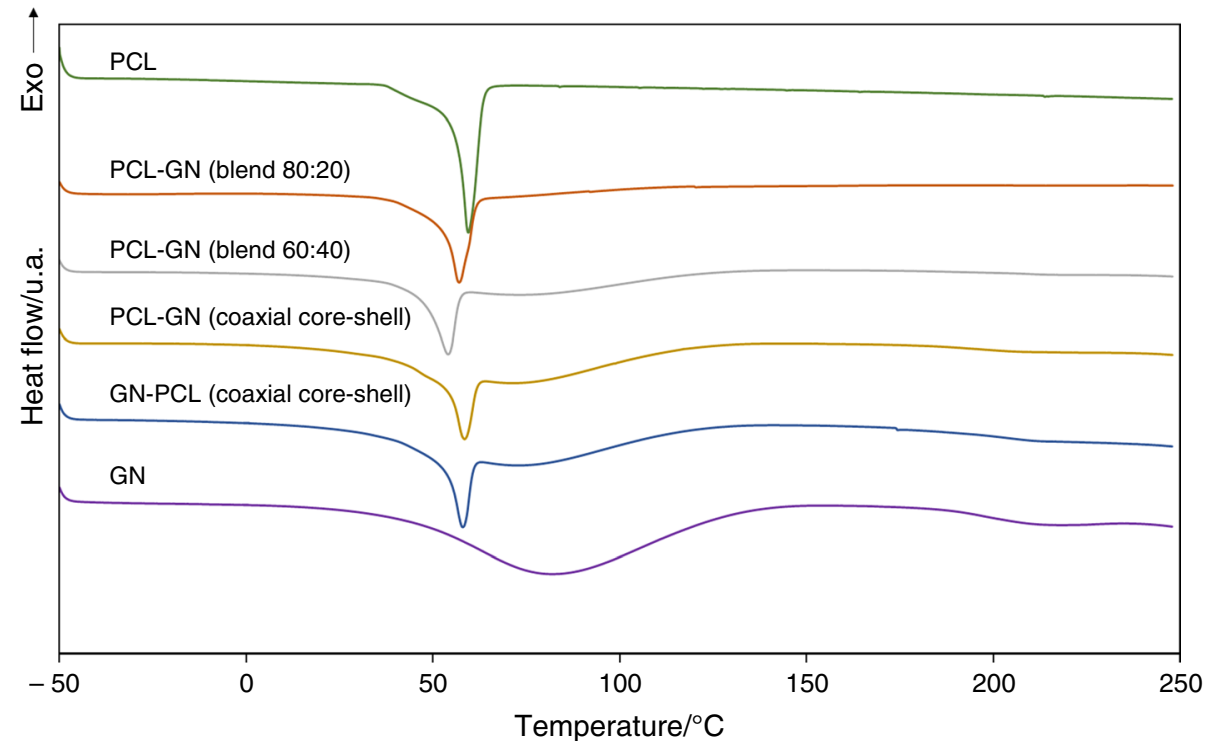

tensile properties of the membranes. The stress-strain curves are shown in Fig. 7.

The main parameters obtained for the different obtained membranes are displayed in Table 3.

The mechanical behavior of the PCL and GN is strongly different. GN is more elastic and, as expected, shows a lower elongation at break than all other compositions. The coaxial systems that are formed by bilayer nanofibers show elastic modulus values between the GN and PCL (111.3 MPa and 17.7 $\mathrm{MPa}$ ) and therefore higher than the pure PCL.

Concerning the strain at break, with this type of morphological configuration, a very strong reduction is detected with respect to the membranes of PCL alone. For the membrane PCL-GN blends, very good results in the tensile properties are detected, the presence of $\mathrm{GN}$ is able to enhance the elastic modulus together with the elongation at break with respect to the pure PCL. This behavior is most likely due to an intimate interaction between GN and PCL. This favorable occurrence seems confirmed in Fig. 5 by the anticipation of the melting point of PCL in the blend.

GN determines the formation of smaller crystallites allowing a better compatibility between GN and PCL in the amorphous phase. This good compatibility confers to PCL chains a better mobility which allows high values of strain. PCL-GN (Blend 80:20) system shows strain at break around $350 \%$ with an increase of about $270 \%$ with respect to the strain at break of the pure PCL. PCL-GN (Blend 60:40) shows a strain at break around the $110 \%$ (still higher than 
Fig. 6 XRD spectra of PCL, PCL-(blend 80:20) and PCL (blend 60:40) samples

Fig. 7 Stress-strain curves
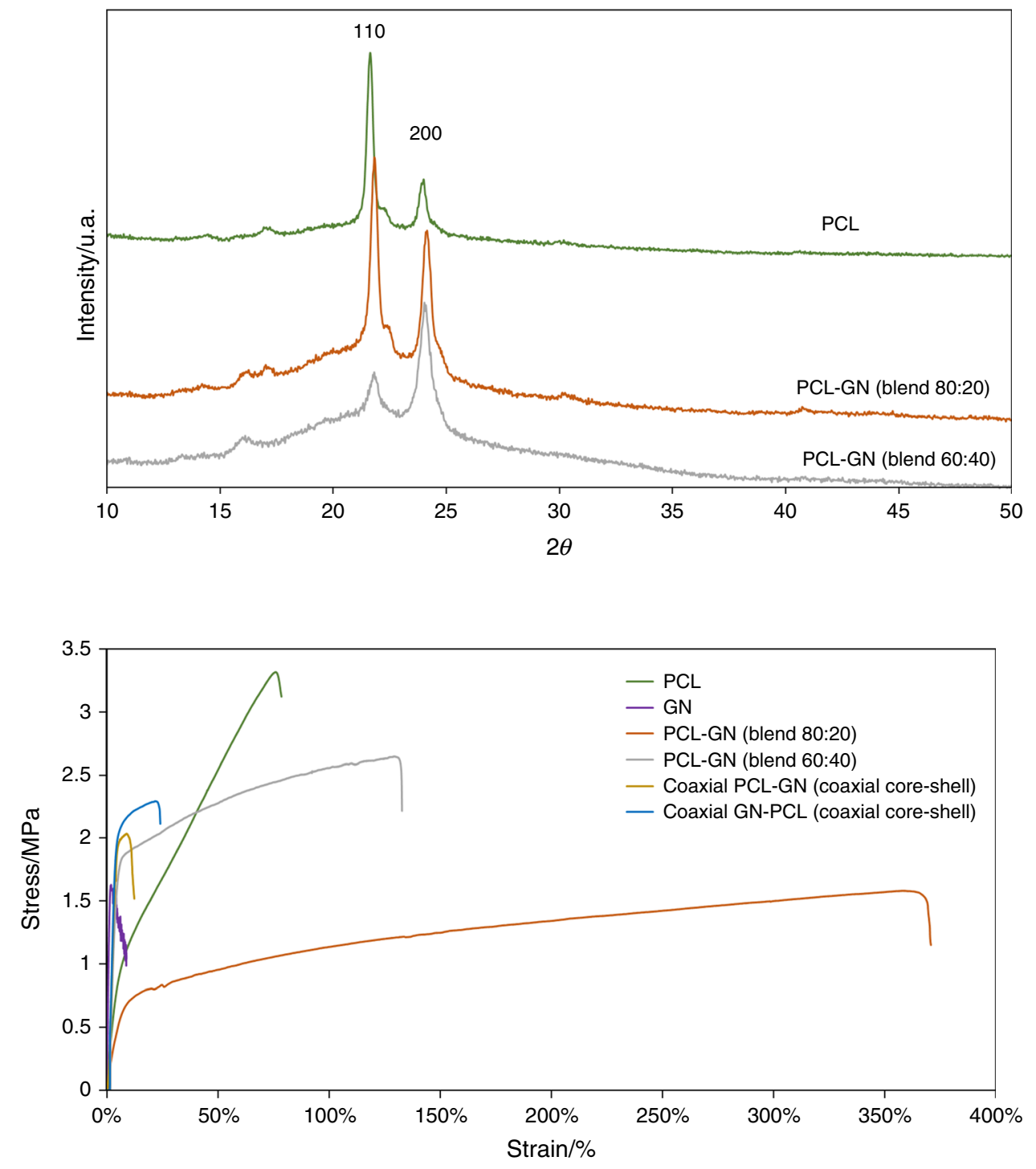

Table 3 Mechanical properties membranes

\begin{tabular}{|c|c|c|c|c|c|c|c|}
\hline & & PCL & GN & $\begin{array}{l}\text { PCL-GN } \\
\text { blend (80:20) }\end{array}$ & $\begin{array}{l}\text { PCL-GN } \\
\text { blend (60:40) }\end{array}$ & $\begin{array}{l}\text { PCL-GN (coaxial } \\
\text { core-shell) }\end{array}$ & $\begin{array}{l}\text { GN-PCL } \\
\text { (coaxial core- } \\
\text { shell) }\end{array}$ \\
\hline \multirow[t]{2}{*}{ Young modulus /MPa } & Mean & 17.7 & 111.3 & 21.3 & 54.5 & 47.35 & 63.3 \\
\hline & Standard deviation & 2.00 & 22.7 & 6.59 & 8.92 & 5.08 & 15.4 \\
\hline \multirow[t]{2}{*}{ Strain at yield $/ \mathrm{mm} \mathrm{mm}^{-1}$} & Mean & 3.88 & 2.34 & 4.27 & 2.72 & 3.71 & 3.78 \\
\hline & Standard deviation & 0.577 & 0.733 & 0.262 & 0.151 & 0.353 & 0.843 \\
\hline \multirow[t]{2}{*}{ Stress at break /MPa } & Mean & 3.16 & 1.97 & 1.99 & 2.14 & 1.84 & 2.3 \\
\hline & Standard deviation & 0.71 & 0.368 & 0.272 & 0.41 & 0.508 & 0.32 \\
\hline \multirow[t]{2}{*}{ Strain at break $/ \mathrm{mm} \mathrm{mm}^{-1}$} & Mean & 78.8 & 3.15 & 349.3 & 112.8 & 10.95 & 22.2 \\
\hline & Standard deviation & 15.7 & 0.980 & 22.8 & 15.1 & 1.76 & 3.78 \\
\hline
\end{tabular}


pure PCL), because even if the crystallites of PCL are even smaller, the GN amount starts to be very high and causes a diminution of the strain at break of the material.

\section{Conclusions}

Electrospun membranes of PCL and GN have been produced, and their characteristics have been compared to PCL-GN blend and coaxial systems. The morphology investigations have revealed no evident defects and an average diameter between 480 and $890 \mathrm{~nm}$ for all the membranes. TGA investigation has evidenced that the membranes obtained from the blends manifest a slightly better thermostability with respect to the membranes obtained by coaxial configuration. The DSC results suggest better compatibility between PCL and GN in the membranes from blends than those prepared by coaxial configuration. In this last case, the interaction between the two components is less intimate because the GN and PCL form bilayer nanofibers. Hence, a minor surface area, only that at the interphase between the fiber layers, is involved in the interaction between the two polymers. This also affects the mechanical properties. The most relevant difference is detected in the elongation at break. For the membranes from the blends an increase up to $110 \%$ and $350 \%$ (depending on the composition) with respect to the membranes of pure PCL is observed. These results, together with data already discussed in the literature on these systems, open up new application scenarios because allowing margins of tolerance to the strain, before the failure, is very high.

\section{Declarations}

Conflict of interest The authors have no conflicts of interest to declare that are relevant to the content of this article.

Open Access This article is licensed under a Creative Commons Attribution 4.0 International License, which permits use, sharing, adaptation, distribution and reproduction in any medium or format, as long as you give appropriate credit to the original author(s) and the source, provide a link to the Creative Commons licence, and indicate if changes were made. The images or other third party material in this article are included in the article's Creative Commons licence, unless indicated otherwise in a credit line to the material. If material is not included in the article's Creative Commons licence and your intended use is not permitted by statutory regulation or exceeds the permitted use, you will need to obtain permission directly from the copyright holder. To view a copy of this licence, visit http://creativecommons.org/licenses/by/4.0/.

\section{References}

1. Hong YJ, Jeong H, Cho KW, Lu N, Kim DH. Wearable and implantable devices for cardiovascular healthcare: from monitoring to therapy based on flexible and stretchable electronics. Adv Funct Mater. 2019;29:1808247.

2. Feiner R, Wertheim L, Gazit D, Kalish O, Mishal G, Shapira A, et al. A stretchable and flexible cardiac tissue-electronics hybrid enabling multiple drug release, sensing, and stimulation. Small. 2019;15:1805526.

3. Guadagno L, Vertuccio L, Barra G, Naddeo C, Sorrentino A, Lavorgna M, et al. Eco-friendly polymer nanocomposites designed for self-healing applications. Polymer. 2021;223:123718.

4. Guadagno L, Vertuccio L, Foglia F, Raimondo M, Barra G, Sorrentino A, et al. Flexible eco-friendly multilayer film heaters. Compos Part B Eng. 2021;224:109208.

5. Gong M, Zhang L, Wan P. Polymer nanocomposite meshes for flexible electronic devices. Prog Polym Sci. 2020;107:101279.

6. Trovato V, Colleoni C, Castellano A, Plutino MR. The key role of 3-glycidoxypropyltrimethoxysilane sol-gel precursor in the development of wearable sensors for health monitoring. J Sol-Gel Sci Technol. 2018;87:27-40.

7. Wang X, Qiu Y, Cao W, Hu P. Highly stretchable and conductive core-sheath chemical vapor deposition graphene fibers and their applications in safe strain sensors. Chem Mater. 2015;27:6969-75.

8. Liu T, Zhu C, Wu W, Liao KN, Gong X, Sun Q, et al. Facilely prepared layer-by-layer graphene membrane-based pressure sensor with high sensitivity and stability for smart wearable devices. J Mater Sci Technol. 2020;45:241-7.

9. Li B, Zhang F, Guan S, Zheng J, Xu C. Wearable piezoelectric device assembled by one-step continuous electrospinning. J Mater Chem C. 2016;4:6988-95.

10. Cicala G, Latteri A, Mannino S, Ognibene G, Blanco I. Influence of soluble electrospun co-polyethersulfone veils on dynamic mechanical and morphological properties of epoxy composites: effect of polymer molar mass. Adv Polym Technol. 2018;37:798-809.

11. Salmeri M, Ognibene G, Saitta L, Lombardo C, Genovese C, Barcellona $\mathrm{M}$, et al. Optimization of $\mathrm{ZnO}$ nanorods growth on polyetheresulfone electrospun mats to promote antibacterial properties. Molecular. 2020;25:1696.

12. Ding Y, Li W, Zhang F, Liu Z, Zanjanizadeh Ezazi N, Liu D, et al. Electrospun fibrous architectures for drug delivery, tissue engineering and cancer therapy. Adv Funct Mater. 2019;29:66.

13. Luraghi A, Peri F, Moroni L. Electrospinning for drug delivery applications: a review. J Control Rel. 2021;334:463-84.

14. Guadagno L, Raimondo M, Longo R, Sarno M, Iuliano M, Mariconda A, et al. Development and characterization of antitumoral electrospun polycaprolactone/functionalized $\mathrm{Fe}_{3} \mathrm{O}_{4}$ hybrid membranes. Mater Today Chem. 2020;17:100309.

15. Longo R, Gorrasi G, Guadagno L. Electromagnetically stimuliresponsive nanoparticles-based systems for biomedical applications: recent advances and future perspectives. Nanomaterials. 2021;11:848.

16. Longo R, Guadagno L, Lamberti P. Electromagnetic characterization of polycaprolactone electrospun nanofibers filled with $\mathrm{Fe}_{3} \mathrm{O}_{4}$ nanoparticles. In: 2020 4th International Symposium Multidisciplinary Studies Innovative Technology; 2020. p. 1-5.

17. Choi S, Han SI, Jung D, Hwang HJ, Lim C, Bae S, et al. Highly conductive, stretchable and biocompatible $\mathrm{Ag}-\mathrm{Au}$ core-sheath nanowire composite for wearable and implantable bioelectronics. Nat Nanotechnol. 2018;13:1048-56.

18. Sampath UGTM, Ching YC, Chuah CH, Sabariah JJ, Lin PC. Fabrication of porous materials from natural/synthetic biopolymers and their composites. Materials. 2016;9:991.

19. de Moraes Porto ICC. Polymer biocompatibility. Polymerization. InTech; 2012. 
20. Munj HR, Lannutti JJ, Tomasko DL. Understanding drug release from PCL/gelatin electrospun blends. J Biomater Appl. 2017;31:933-49.

21. Vert M. Biopolymers and artificial biopolymers in biomedical applications, an overview. Biorelated Polym. 2001;66:63-79.

22. Coimbra P, Santos P, Alves P, Miguel SP, Carvalho MP, de Sá KD, et al. Coaxial electrospun PCL/Gelatin-MA fibers as scaffolds for vascular tissue engineering. Colloids Surf B Biointerfaces. 2017;159:7-15.

23. Adeli-Sardou M, Yaghoobi MM, Torkzadeh-Mahani M, Dodel M. Controlled release of lawsone from polycaprolactone/gelatin electrospun nano fibers for skin tissue regeneration. Int J Biol Macromol. 2019;124:478-91.

24. Gautam S, Dinda AK, Mishra NC. Fabrication and characterization of PCL/gelatin composite nanofibrous scaffold for tissue engineering applications by electrospinning method. Mater Sci Eng C. 2013;33:1228-35.

25. Yao R, He J, Meng G, Jiang B, Wu F. Electrospun PCL/Gelatin composite fibrous scaffolds: mechanical properties and cellular responses. J Biomater Sci Polym Ed. 2016;27:824-38.

26. Zhang Y, Ouyang H, Chwee TL, Ramakrishna S, Huang ZM. Electrospinning of gelatin fibers and gelatin/PCL composite fibrous scaffolds. J Biomed Mater Res Part B Appl Biomater. 2005;72:156-65.

27. Rashid TU, Gorga RE, Krause WE. Mechanical properties of electrospun fibers-a critical review. Adv Eng Mater. 2021;23:2100153.
28. Havlíček K, Svobodová L, Bakalova T, Lederer T. Influence of electrospinning methods on characteristics of polyvinyl butyral and polyurethane nanofibres essential for biological applications. Mater Des. 2020;194:108898.

29. Boland ED, Coleman BD, Barnes CP, Simpson DG, Wnek GE, Bowlin GL. Electrospinning polydioxanone for biomedical applications. Acta Biomater. 2005;1:115-23.

30. Persenaire O, Alexandre M, Degée P, Dubois P. Mechanisms and kinetics of thermal degradation of poly( $\varepsilon$-caprolactone). Biomacromol. 2001;2:288-94.

31. Correia DM, Padrão J, Rodrigues LR, Dourado F, Lanceros-Méndez S, Sencadas V. Thermal and hydrolytic degradation of electrospun fish gelatin membranes. Polym Test. 2013;32:995-1000.

32. Feng L, Kamal MR. Distributions of crystal size from DSC melting traces for polyethylenes. Can J Chem Eng. 2004;82:1239-51.

33. Baji A, Wong SC, Liu T, Li T, Srivatsan TS. Morphological and $\mathrm{X}$-ray diffraction studies of crystalline hydroxyapatite-reinforced polycaprolactone. J Biomed Mater Res Part B Appl Biomater. 2007;81:343-50.

Publisher's Note Springer Nature remains neutral with regard to jurisdictional claims in published maps and institutional affiliations. 